\title{
Assessment of the Outcome of Refeeding Syndrome Patients Admitted to Intensive Care Unit
}

\author{
Naser Gharebaghi', Mohammad Amin Valizade Hasanloei ${ }^{2, *}$, Alireza Mehdizade \\ Khalifani $^{3}$, Naser Moshiri ${ }^{4}$, Faiezeh Hejazifar ${ }^{5}$
}

${ }^{I}$ Assistant Professor, Department of Infectious Diseases, School of Medicine, Urmia University of Medical Sciences, Urmia, Iran

${ }^{2}$ Associate Professor, Department of Anesthesiology, School of Medicine, Urmia University of Medical Sciences, Urmia, Iran

${ }^{3}$ Assistant Professor, Department of Endocrinology and Metabolism, School of Medicine, Urmia University of Medical Sciences, Urmia, Iran

${ }^{4}$ Specialist of Infectious Diseases, Urmia University of Medical Sciences, Urmia, Iran

${ }^{5}$ General Practitioner, Urmia University of Medical Sciences, Urmia, Iran

* Corresponding Author: Mohammad Amin Valizade Hasanloei, Intensive Care Unit, Imam Hospital, Urmia, Iran. Email: aminvalizade@yahoo.com

Received: 22.01 .2018

Accepted: 16.04 .2018

\section{How to Cite this Article:}

Gharebaghi N, Valizade

Hasanloei MA, Mehdizade

Khalifani A, Moshiri N,

Hejazifar F. Assessment of the

Outcome of Refeeding Syn-

drome Patients Admitted to

Intensive Care Unit. Avicenna J

Clin Med. 2018; 25(1): 56-62.

DOI: $10.21859 /$ ajcm.25.1.56.

\section{Abstract}

Background and Objective: Refeeding syndrome (RFS) is comprised of severe electrolyte disturbances and metabolic abnormalities that occur after the reinstitution of nutrition to starved patients.

Materials and Methods: This prospective study was conducted on patients aged over 18 years who were admitted to the Intensive Care Unit (ICU) of Taleghani and Emam hospitals in Urmia, Iran, during the first half of 2017. The included participants had the ICU stay of more than $48 \mathrm{~h}$, were kept on nil per os, and were under nutritional support. The patients' serum levels of phosphorus, magnesium, and potassium were measured on the $1^{\text {st }}, 3^{\text {rd }}$, and $7^{\text {th }}$ days of hospital stay. The frequency of RFS, hypophosphatemia, hypomagnesemia, hypokalemia, and the short-term outcomes of patients were obtained and compared. The patients with acute and chronic renal failure, cancer, previous gastrointestinal and hepatic diseases, and electrolyte disorder were excluded from the study.

Results: The mean length of ICU stay and duration of mechanical ventilation were 35 and 28.5 days, respectively. The frequency of mortality among the patients was $36.96 \%(\mathrm{n}=95)$. Furthermore, RFS, hypophosphatemia, hypokalemia, and hypomagnesemia had the frequencies of $13.23 \%, 25.7 \%$, $21.4 \%$, and $37.7 \%$, respectively. There were significant differences between the patients with RFS and those without RFS in terms of the body mass index, duration of mechanical ventilation, ICU length of stay, and mortality $(\mathrm{P}<0.05)$.

Conclusion: In this study, despite the differences of our findings with those of the literature, the frequency of electrolyte disturbances during the onset of re-feeding was within an acceptable range.

Keywords: Electrolyte Disturbances, Nutritional Support, Refeeding Syndrome 


\section{ارزيابى بيامل بيمار ان با نشانتان تغذيه مجدد بسترى در بخش مر اقبتهاى ويثره}

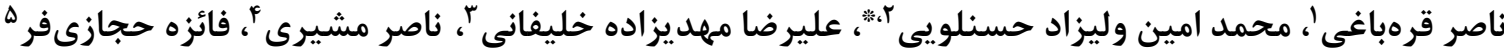

' استاديار، كروه بيمارىهاى عفونى، دانشكده يزشكى، دانشعاه علوم يزشكى اروميه، اروميه، ايران

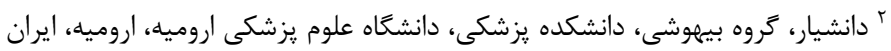

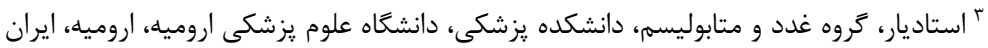

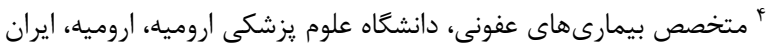

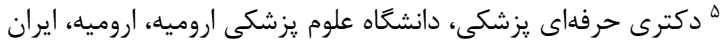
* نويسنده مسئول: محمد امين وليزاد حسنلويى، بخش مراقبتهاى ويزه، بيمارستان امام، اروميه، ايران. ايميل: yaminvalizade@yahoo.com

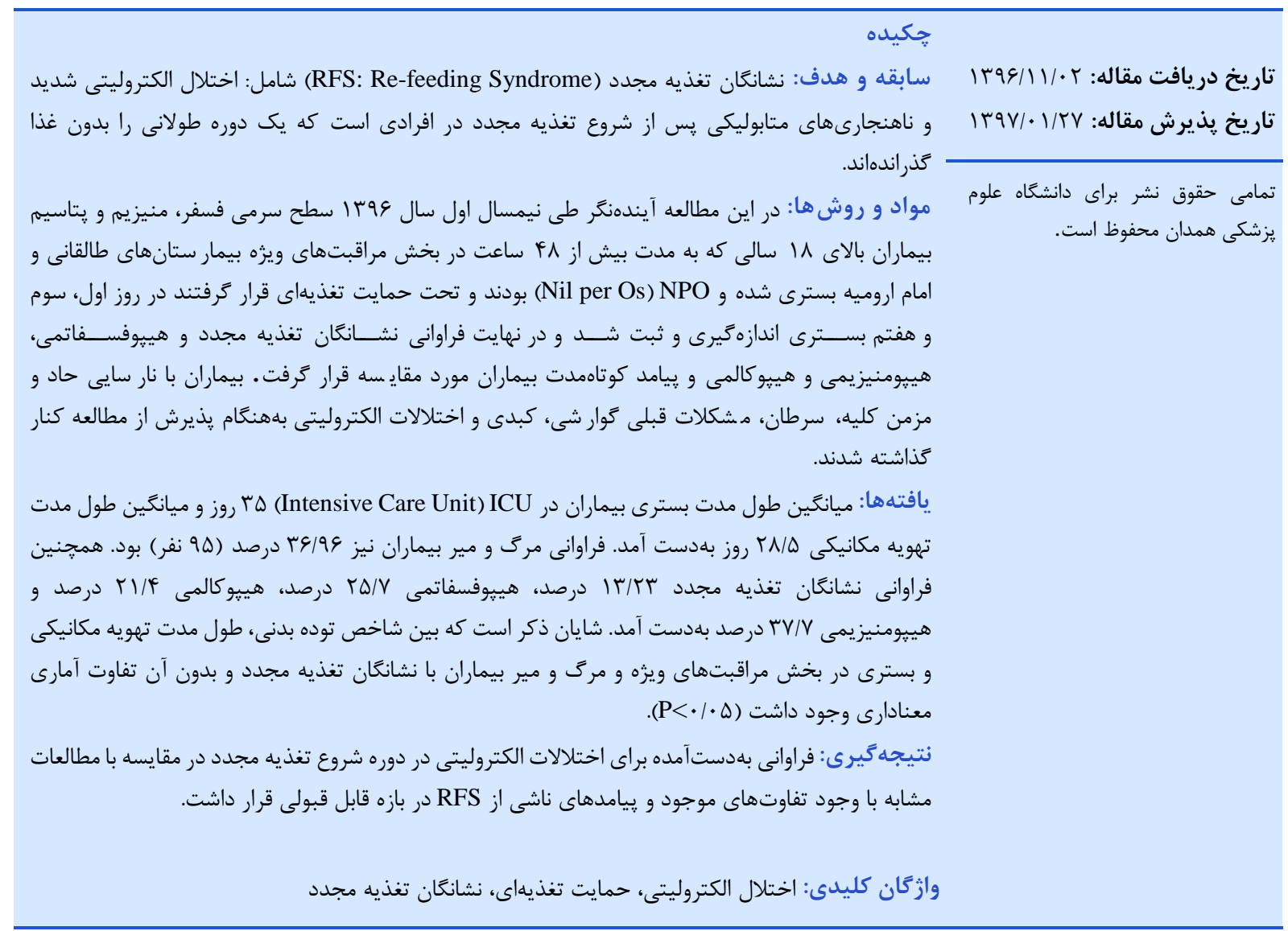

مجدد قرار مى گيرند، مى باشد [r.r].

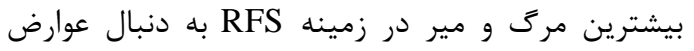

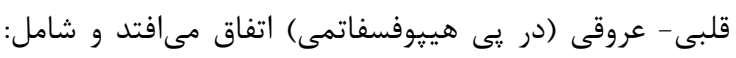

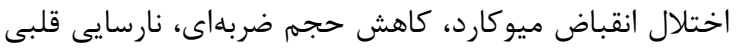

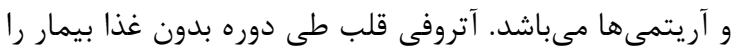

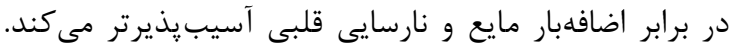

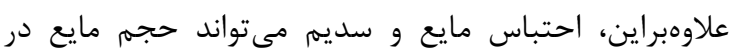

نشانگان تغذيه مجدد بهعنوان عوارض بالينى ناشى از

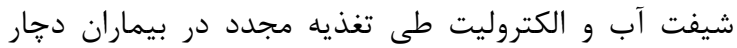

سوءتغذيه تعريف مىشود [1].] RFS بهطور گسترده شامل: اختلال الكتروليتى شديد (بهطور عمده غلظت كمم يونهاى داخل سلولى مانند فسفات،

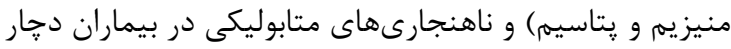

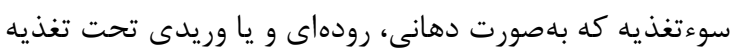


نارسايى قلبى شدند، توصيف كرديد [•[1]. در حقيقت،

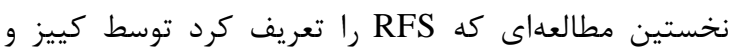

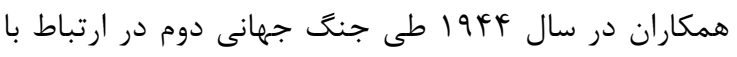

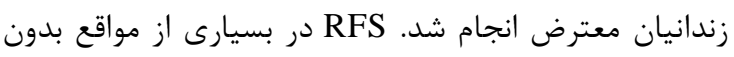

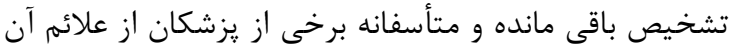

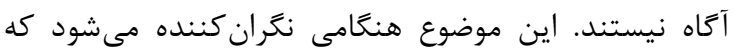
RFS بهعنوان يك وضعيت تهديدكننده حيات شناخته

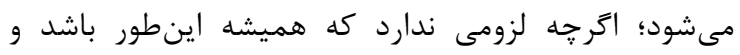

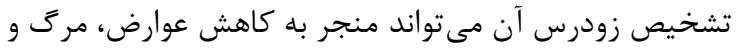

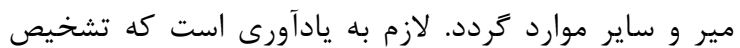

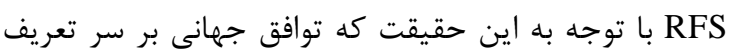

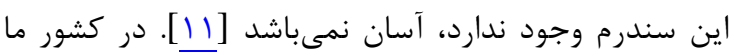

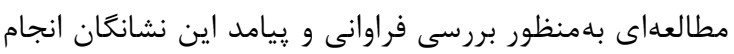

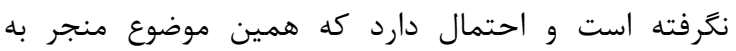
تشخيص كمتر از حد واقعى و يا درمان نامتناسب اين نشانكان المدان

\section{مواد و روشها}

بِّ از تصويب طرح در كميته اخلاق دانشكاه، طى يك

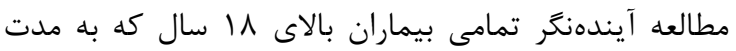

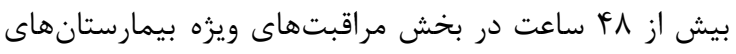

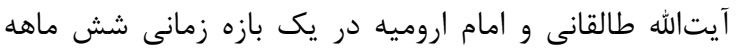

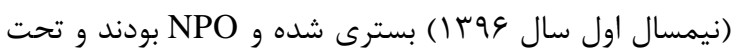
حمايت تغذيهاى قرار داشتند، وارد مطالعه شدند. بيماران مباد مبتلا

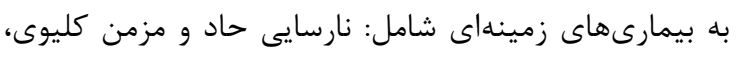

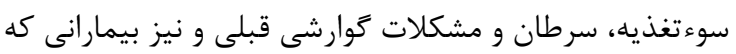

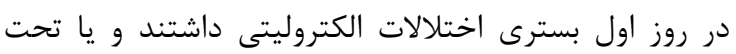

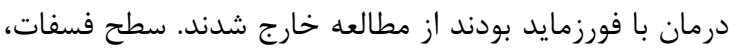

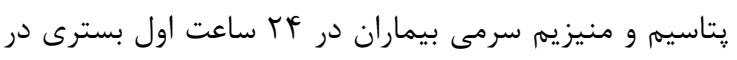

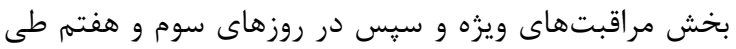

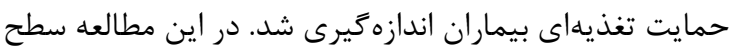

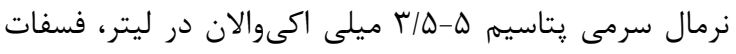
| بر دسى ليتر در نظر كرفته شده است

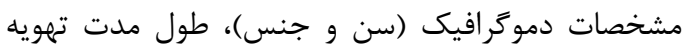

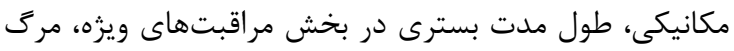

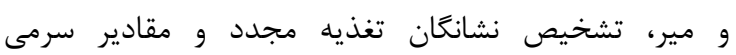

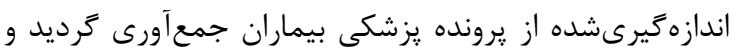

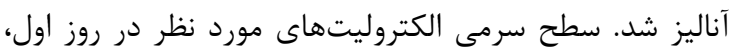

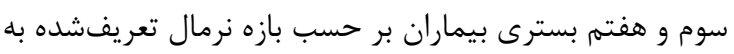

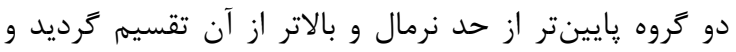

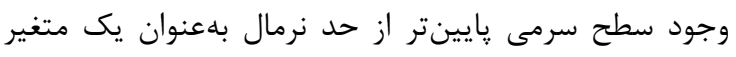

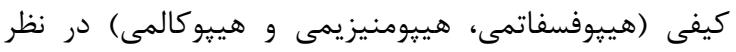

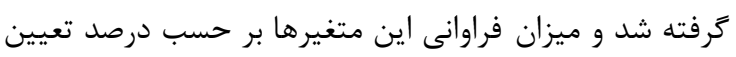

كَرش را افزايش داده و منجر به اضافهبار مايع با آتروفى قلبى

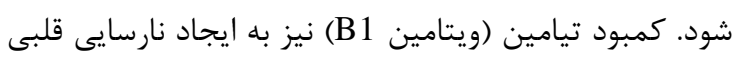

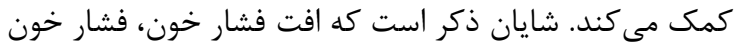

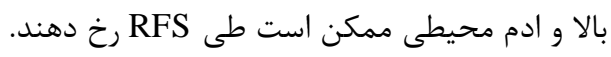

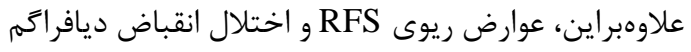

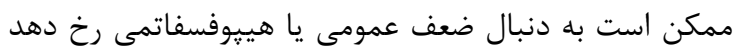

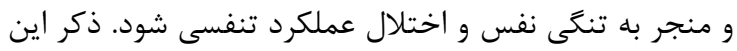

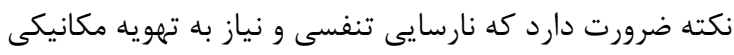

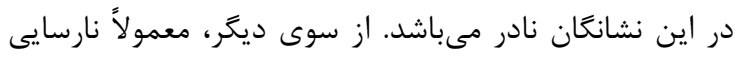

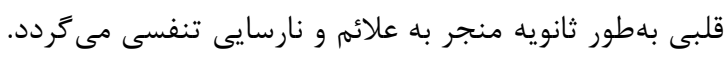

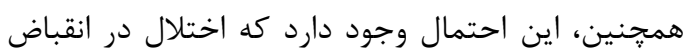

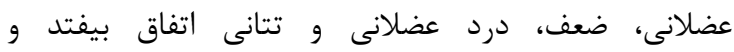

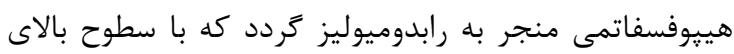
كراتين فسفوكيناز مشخص مى شيود.

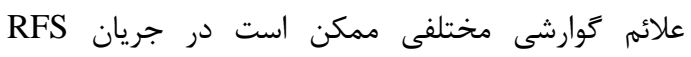

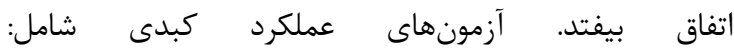
Alanine) ،AST (Aspartate Aminotransferase) ALT (Aminotransferase

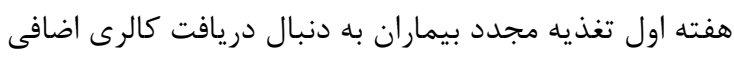

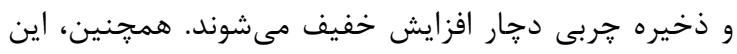

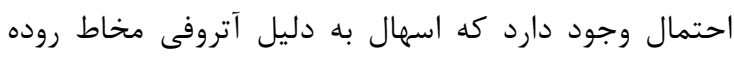

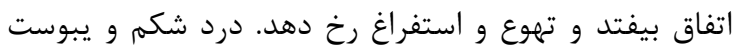

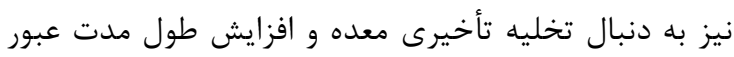
محتويات كولون محتمل مىباشد.

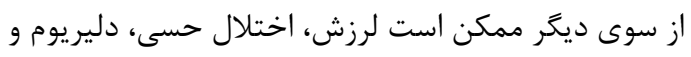

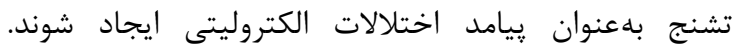

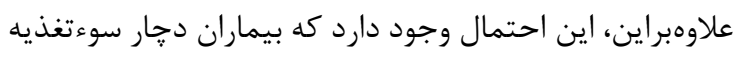

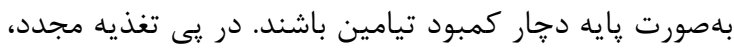

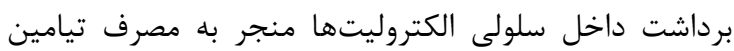

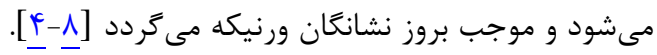

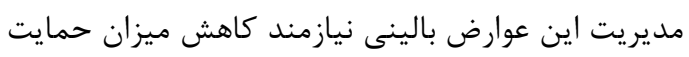
تغذيهاى و تصحيح هيبوفسفاتمى، هيبومنيزيمى و هيبيو كالمى دئي

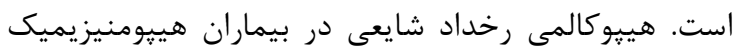

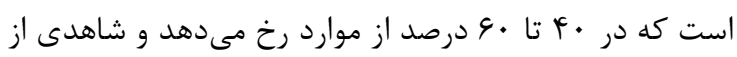

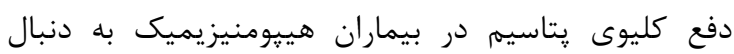

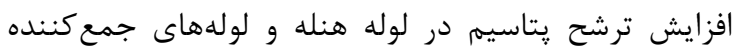

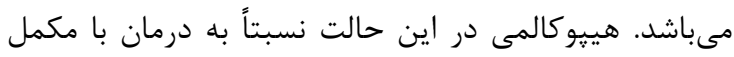

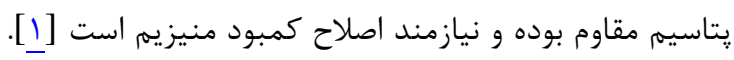

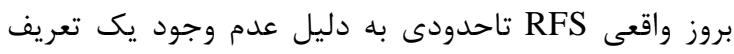

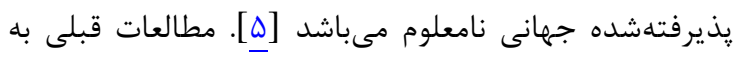

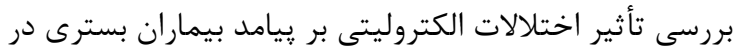

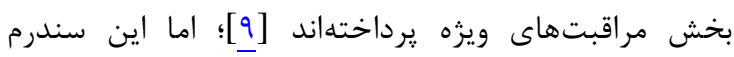

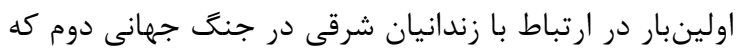

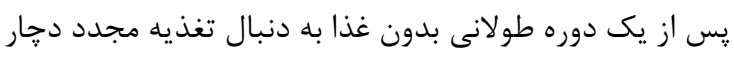


سه نفر به دليل سن كمتر از \| سال، ع ب نفر به علت اختلال

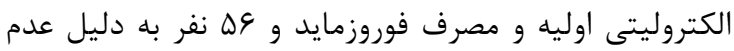
اندازهزيرى الكتروليتهاى مورد نظر از مطالعه حذف گر ديدند

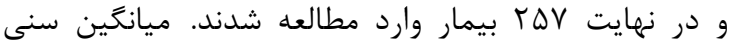
بيماران مورد مطالعه ميانگين شاخص توده بدنى

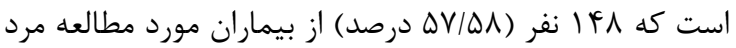

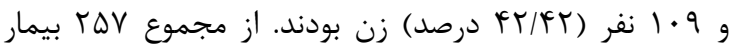

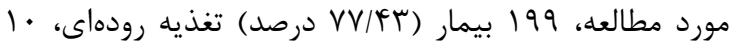

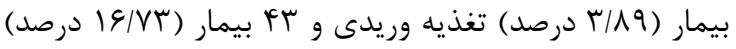

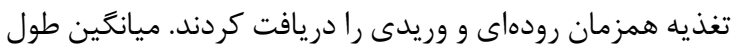

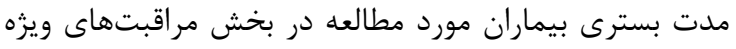

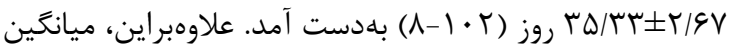

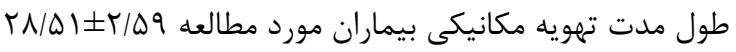

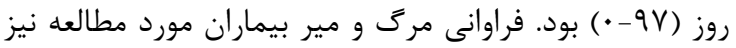

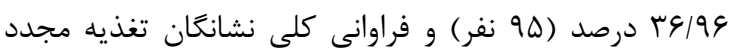

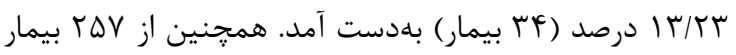

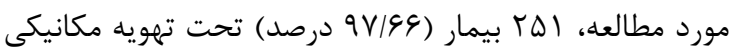
قرار گرفتند و شش نفر باقى مانده آن را دريافت نكردند.

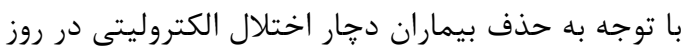

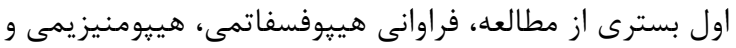

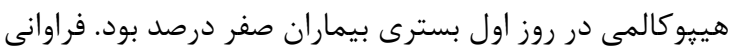

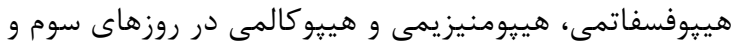

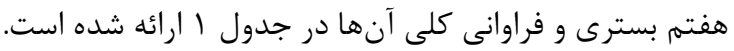

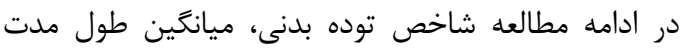
تهويه مكانيكى و طول مدت بسترى در بخش مراقبتهاى ويزه و

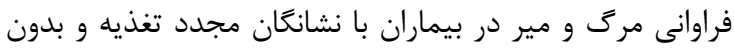

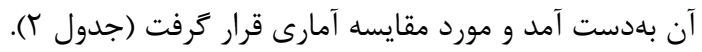

كرديد. جهت تعيين فراوانى كلى متغيرهاى مذكور، ميانگين

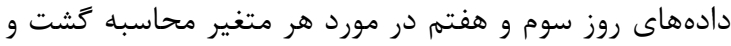

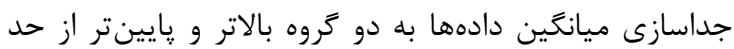

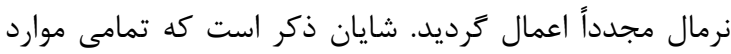

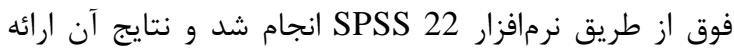

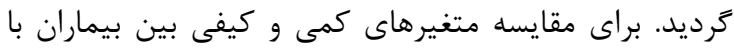

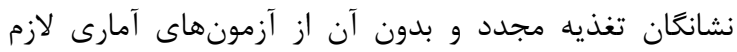

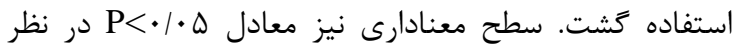

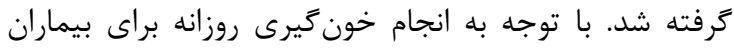

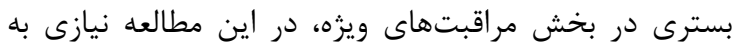

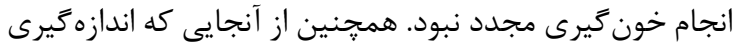

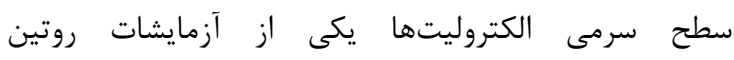
درخواستشده در بيمارستان ها مىباشد، هزينه مازاد بر بيماران

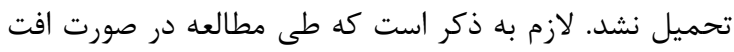

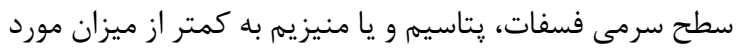

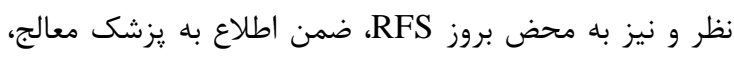

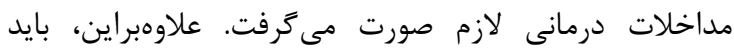
خاطرنشان ساخت كه بيماران مشكوك به نشانعان تغذيه مجدمد (براساس سطح سرمى الكتروليتها و علائم بالينى نظير ادم،

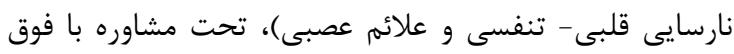

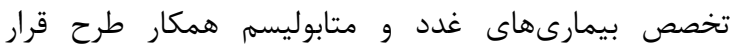
مى ترفتند.

\section{يافته ها}

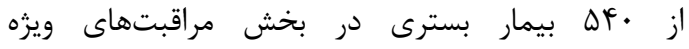

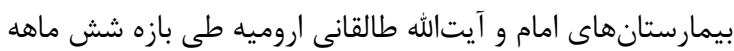

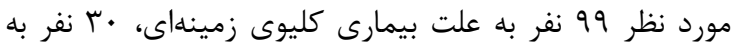

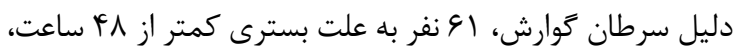

جدول ا: حداقل، حداكثر و ميانكين با انحراف معيار سطوح فسفر، منيزيم و پتاسيم در روز اول، سوم و هفتم بسترى بيماران و فراوانى هييوفسفاتمى،

\begin{tabular}{|c|c|c|c|c|c|}
\hline فراوانى هييوفسفاتمى (درصد) & انحر اف معيار & 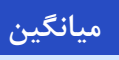 & حداكثر & حداقل & \\
\hline$\cdot$ & $\cdot 190$ & $r / r r$ & $\Delta / T V$ & $r / \Delta$ & سطح فسفر روز اول \\
\hline$r \varphi / Q$ & $\cdot / V V$ & $r / F$ & $\Delta / 9$ & $1 / \cdots$ & سطح فسفر روز سوم \\
\hline$T T / V$ & $\cdot 119$ & T/Aৎ & G/TD & $\cdot / \Delta \omega$ & سطح فسفر روز هفتم \\
\hline$r \Delta / V$ & - & - & - & - & فراوانى كلى هيبوفسفاتمى \\
\hline · & $\cdot|r|$ & $1 / 19$ & $r / \mathcal{F}$ & $1 / 1$ & سطح منيزيم روز اول \\
\hline$F \cdot 1 Q$ & $\cdot / \pi \Delta$ & $1 / V r$ & $r / 9$ & $\cdot 194$ & سطح منيزيم روز سوم \\
\hline$F \Delta / 1$ & $\cdot / 49$ & $1 / 91$ & $\Gamma / 1 \Lambda$ & $\cdot 19 \Delta$ & سطح منيزيم روز هفتم \\
\hline$r V / V$ & - & - & - & - & فراوانى كلى هيبومنيزيمى \\
\hline$\cdot$ & $\cdot / r v$ & T/AT & $\Delta / \Delta$ & $r / \Delta$ & سطح پتاسيم روز اول \\
\hline$r q / r$ &.$/ 49$ & $r / 99$ & $\Delta / \Gamma$ & r & سطح يتاسيم روز سوم \\
\hline r & $\cdot / 4 \wedge$ & $r / V r$ & $\Delta / r$ & $r / T$ & سطح يتاسيم روز هفتم \\
\hline$r I / F$ & - & - & - & - & فراوانى كلى هيبوكالمى \\
\hline
\end{tabular}


جدول r: ميانكَين و انحراف معيار شاخص توده بدنى، تهويه مكانيكى، بسترى در بخش مراقبتهاى ويزه و مرگ و مير بيماران در دو گروه با نشانكان تغذيه مجدد و بدون آن

\begin{tabular}{|c|c|c|}
\hline سطح معنادارى & ميانكين土|نحر اف معيار & \\
\hline$\cdot 1 \cdot r$ & $\begin{array}{l}|N / \cdot| \pm I / r \\
r F / V G \pm T / Y F\end{array}$ & 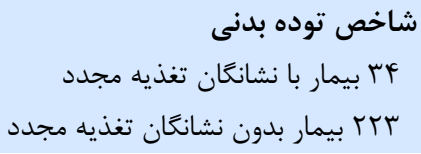 \\
\hline$\cdot 1 \cdot r$ & $\begin{array}{l}r q / \mid V \pm F / \Lambda \\
r \xi /|r \pm g / r|\end{array}$ & 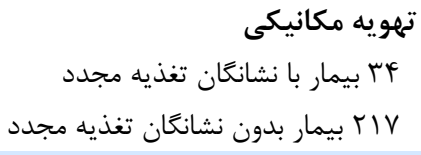 \\
\hline$\cdot 1 \cdot 1$ & $\begin{array}{l}r \cdot / 4 q \pm V / l r \\
r q / V I \pm N / T\end{array}$ & 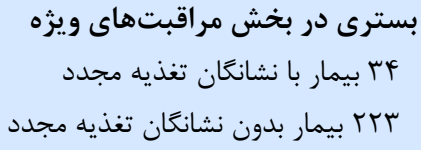 \\
\hline$\cdot 1 \cdot \cdot 1$ & $\begin{array}{l}(\Delta \Delta / q) 19 \\
(r \Delta / \cdot r) \vee G\end{array}$ & 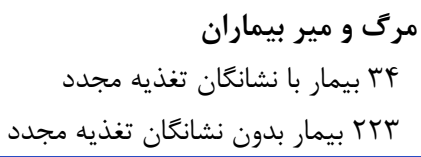 \\
\hline
\end{tabular}

در بخش مراقبتهاى ويزه در بيماران داراى RH طولانى تر از

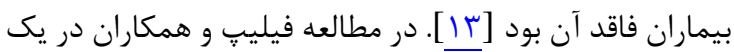
بيمارستان سطح سه در شمال شرقى هند نيز طى يك دور دوره

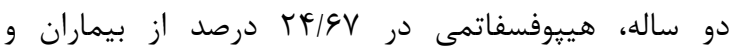

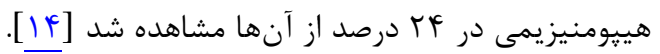

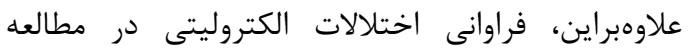

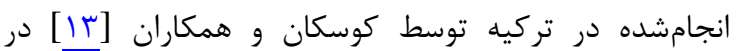
مقايسه با مطالعه حاضر بيشتر بود؛ درحالى كه دئه ميزان

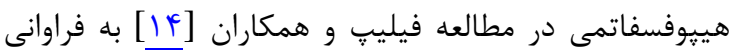

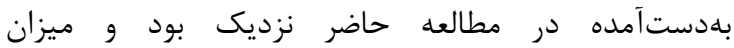
هييومنيزيمى كمتر از فراوانى مشاهدهشده در مطالعه حاضر درد

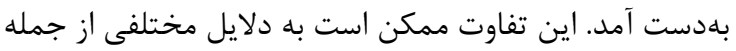

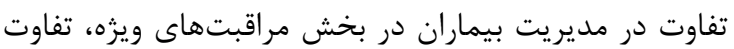

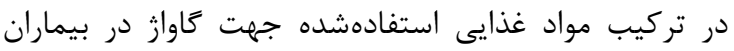
تحت تغذيه رودهاى، تفاوت در بيماران واردشده به مطالعهها

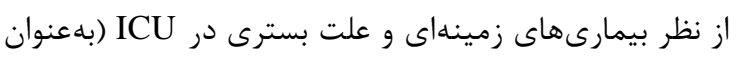

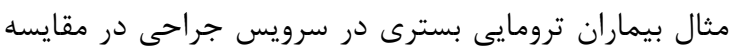

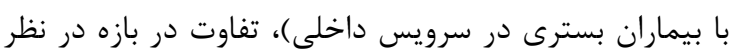

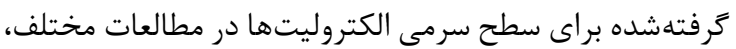

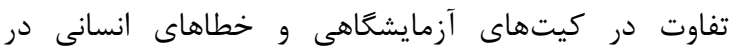
اندازهكيرى الكتروليتها و غيره باشد.

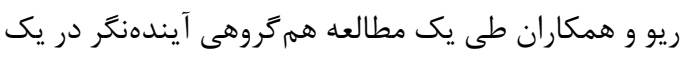

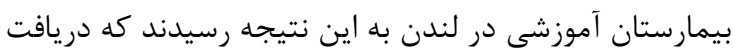

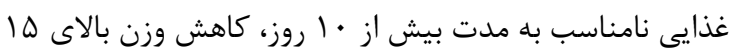

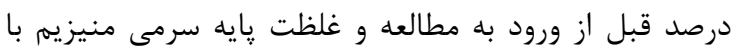

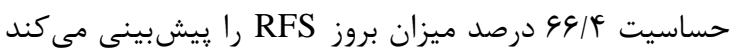

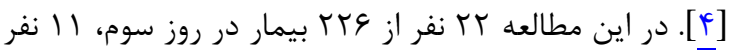

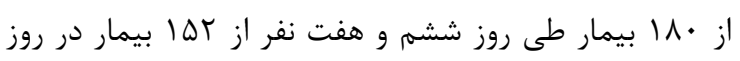

نشانگان تغذيه مجدد به خوبى شرح داده شده است؛ اما در

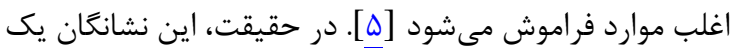

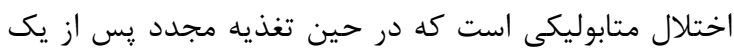

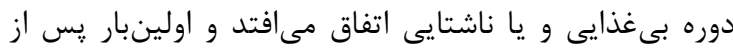

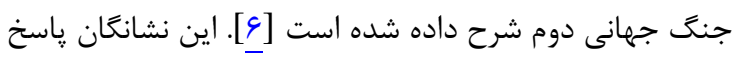

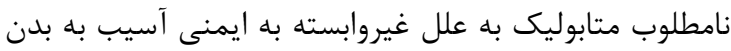

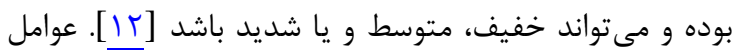

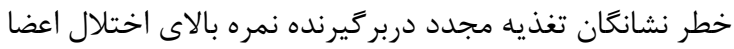

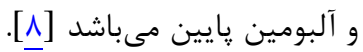

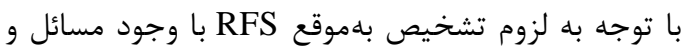

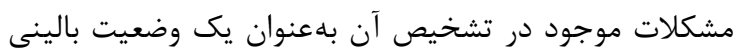

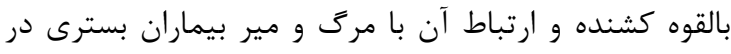
بخش مراقبتهاى ويزه، مطالعه حاضر به بررسى ميزان فراوانى و

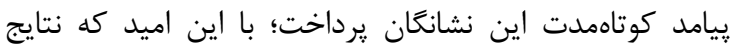

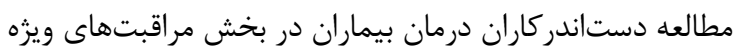
را جهت اقدام بهموقع و ايجاد ظن بالينى معقول راهنمايى نمايد.

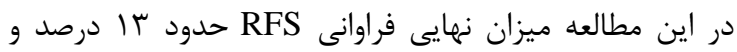

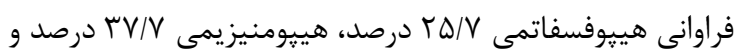

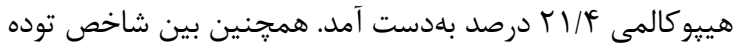
بدنى، طول مدت تهويه مكانيكى و بسترى در بخش مراقبت مهاى

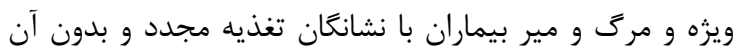
تفاوت آمارى معنادارى وجود داشت (ه • P P (P).

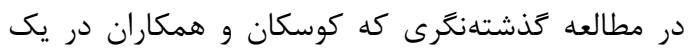
مركز مراقبتهاى ويزه در كشور تركيه انجام دادند، ميزان بروز ،

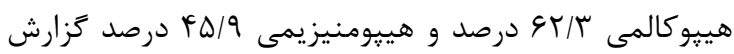
كرديد. در اين مطالعه تفاوت واضحى در ميزان بروز RH بين

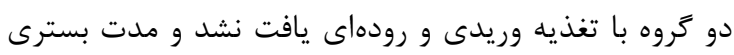


[1 [1]. در مطالعه فوق ميزان بروز RH معادل ها ا درصد بهدست

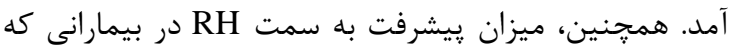

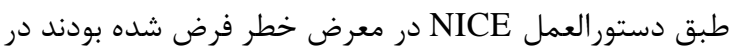
زروه تغذيه رودهاى بيشتر از زروه تغذيه وريدى دور بود. شايان

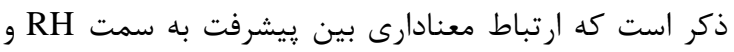

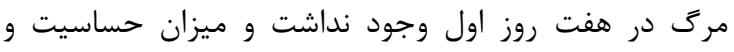

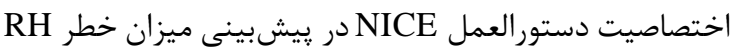

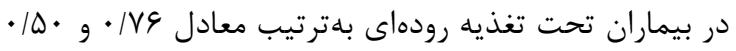

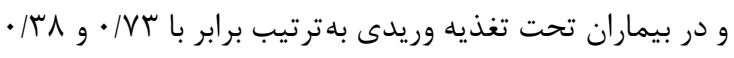

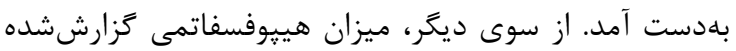

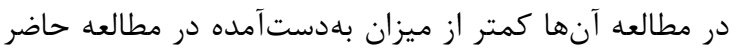

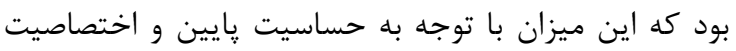

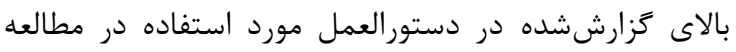

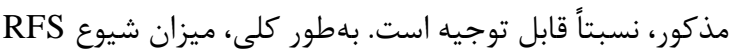

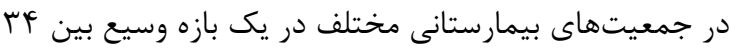

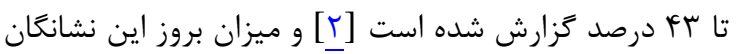

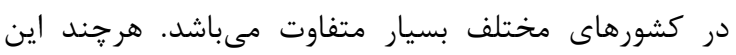

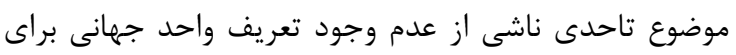

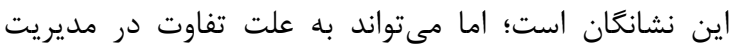

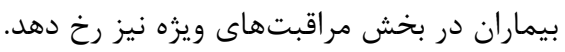

\section{نتيجه تيرى}

در مطالعه حاضر ميزان بروز اختلالات الكتروليتى و نشانكان

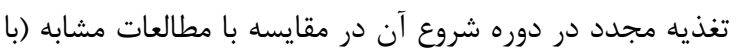

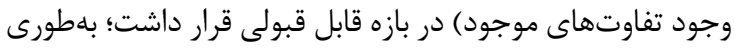

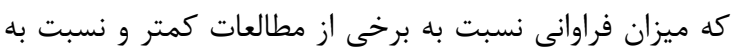

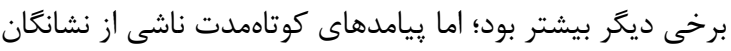
تغذيه مجدد با مطالعات قبلى همسويى داشت.

\section{تشكر و قدر فاذى}

اين مقاله بركرفته از طرح تحقيقاتى مصوب دانشعاه علوم

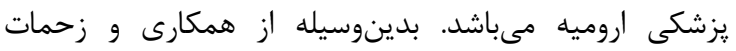

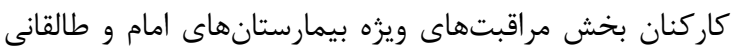

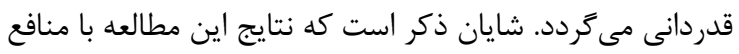
نويسندًان در تعارض نمىباشد.

\section{REFERENCES}

1. Mehler P. Anorexia nervosa in adults and adolescents: the refeeding syndrome. Waltham, MA: UpToDate; 2013. P. 4, 46, 230, 114.

2. Crook MA. Refeeding syndrome: problems with definition and management. Nutrition. 2014;30(11-12):1448-55. PMID: 25280426 DOI: 10.1016/j.nut.2014.03.026

3. Boland K, Solanki D, O'Hanlon C. Prevention and treatment of refeeding syndrome in the acute care setting. Dublin: Irish Society for Clinical Nutrition \& Metabolism; 2013.

4. Rio A, Whelan K, Goff L, Reidlinger DP, Smeeton N. Occurrence of refeeding syndrome in adults started on artificial nutrition support: prospective cohort study.

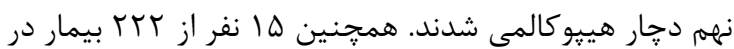

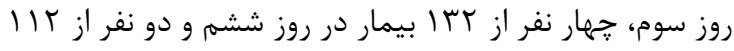

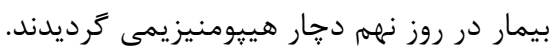

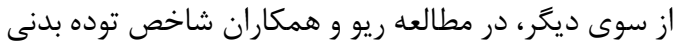
بيماران مورد مطالعه جهت تعيين ريسك ابتلا به

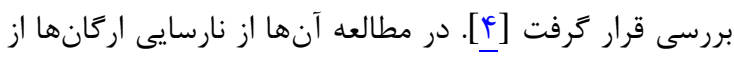

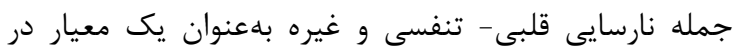

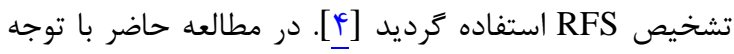

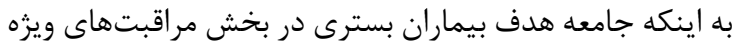

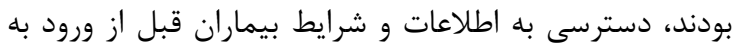

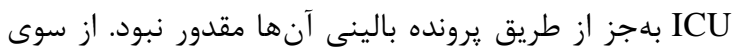

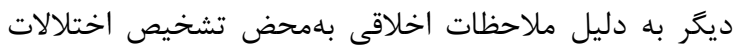

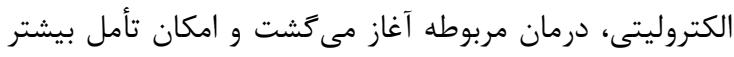

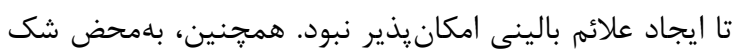

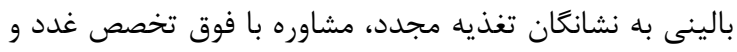

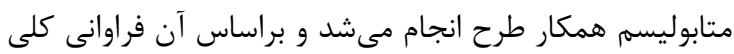

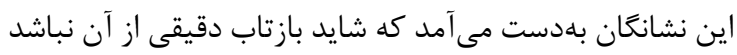

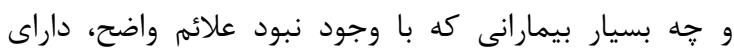

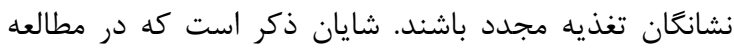
حاضر شاخص توده بدنى، مدت زمان تهويه مكانيكى و بسترى دئن

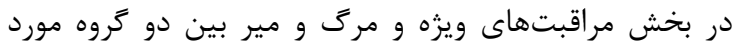
مطالعه تفاوت آمارى واضحى داشت. در اين زمينه، در مطالعه بصرى و همكاران ميزان دان بروز

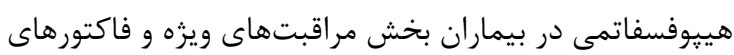

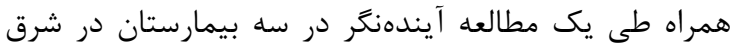

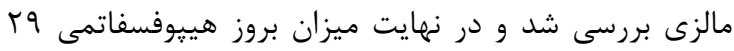

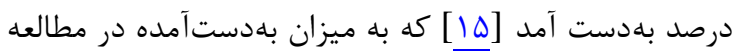
حاضر نزديك مىباشد. از سوى ديخر در مطالعه زكى و همكاران بروز كلى RH و نرديل

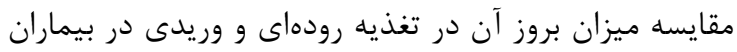
بسترى و نيز بررسى اختصاصيت و حساسيت تعيين ميزان خطر ييشرفت به سمت RH در بيماران در معرض خطر توسط بر

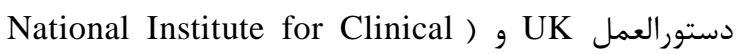
NICE (Excellence طH بسترى در بخش مراقبتهاى ويزه مورد بررسى قرار كرفت

BMJ Open. 2013;3(1):e02173. PMID: 23315514 DOI: 10.1136/bmjopen-2012-002173

5. Mehana HM, Moledina J, Travis J. Refeeding syndrome: what it is and how to prevent and treat it. BMJ. 2008;336(7659):1495-8. PMID: 18583681 DOI: 10.1136/bmj.a301

6. Olthof LE, Koekkoek WK, van Setten C, Kars JC, van Blokland D, van Zanten AR. Impact of caloric intake in critically ill patients with, and without, refeeding syndrome: Aa retrospective study. Clin Nutr. 2017;10:1-9. DOI: 10.1016/j.clnu.2017.08.001

7. Alfaro Martínez JJ, Huguet Moreno I, Botella Romero F, 
Hernández López A. Etiology and Complications of Refeeding Syndrome in the ICU. Diet Nutr Crit Care. 2014;2:1-6.

8. Mbbchbao MB. Refeeding hypophosphataemia after enteral nutrition in a Malaysian intensive care unit: risk factors and outcome. Asia Pacific J Clin Nutr. 2018;27(2):329-35.

9. Mousavi SA, Shahabi S, Mostafapour E, Purfakharan M, Fereshtehnejad SM, Amini J, et al. Comparison of the serum electrolyte levels among patients died and survived in the intensive care unit. Tanaffos. 2012;11(4):36-42. PMID: 25191436

10. Viana LA, Burgos MG, Silva Rde A. Refeeding syndrome: clinical and nutritional relevance. Arq Bars Cir Dig. 2012;25(1):56-9. PMID: 22569981

11. Kraft MD, Btaiche IF, Sacks GS. Review of the refeeding syndrome. Nutr Clin Pract. 2005;20(6):625-33. PMID: 16306300 DOI: $10.1177 / 0115426505020006625$

12. Khan LU, Ahmed J, Khan S, Macfie J. Re-feeding syndrome: a literature review. Gastroenterol Res Pract. 2011;2011:1-6. PMID: 20886063 DOI: 10.1155/2011/410971

13. Cuskun R, Gundogan K, Baldane S, Guven M, Sungur M. Refeeding hypophosphatemia: a potentially fatal danger in the intensive care unit. Turk J Med Sci. 2014;44(3):369-74. PMID: 25558635

14. Philip CC, John M, Abraham J. Magnesium, calcium and phosphorus in the intensive care unit: do we need to monitor? Arch Med Biomed Res. 2014;1(3):96-102.

15. Basri MN, Janattul AJ, Azrina MR, Hadi MA. Hypophosphatemia in the intensive care unit: incidence, predictors and management. Int Med $J$ Malaysia. 2012;11(1):31-6.

16. Zeki S, Culkin A, Gabe SM, Nightingale JM. Refeeding hypophosphatemia is more common in enteral than parenteral feeding in adult in patients. Clin Nutr. 2011;30:365-8. PMID: 21256638 DOI: $10.1016 /$ j.clnu.2010.12.001 